Research Paper

\title{
Effects of Osteogenic-Conditioned Medium from Human Periosteum-Derived Cells on Osteoclast Differentiation
}

Hyun-Chang Park ${ }^{*}$, Young-Bum Son ${ }^{*}$, Sung-Lim Lee², Gyu-Jin Rho², Young-Hoon Kang1, Bong-Wook Park1, Sung-Hoon Byun', Sun-Chul Hwang 3 , In-Ae Cho ${ }^{4}$, Yeong-Cheol Cho ${ }^{5}$, Iel-Yong Sung 5 , Dong Kyun Woo $^{6 \bowtie}$, June-Ho Byun ${ }^{1 凶}$

1. Department of Oral and Maxillofacial Surgery, Gyeongsang National University School of Medicine and Gyeongsang National University Hospital, Institute of Health Sciences, Gyeongsang National University, Jinju, Republic of Korea;

2. Department of Theriogenology and Biotechnology, College of Veterinary Medicine, Gyeongsang National University, Jinju, Republic of Korea;

3. Department of Orthopaedic Surgery, Institute of Health Sciences, Gyeongsang National University School of Medicine, Jinju, Republic of Korea

4. Department of Obstetrics and Gynecology, Gyeongsang National University School of Medicine and Gyeongsang National University Hospital, Institute of Health Sciences, Gyeongsang National University, Jinju, Republic of Korea;

5. Department of Oral and Maxillofacial Surgery, College of Medicine, Ulsan University Hospital, University of Ulsan, Ulsan, Republic of Korea;

6. College of Pharmacy and Research Institute of Pharmaceutical Sciences, Gyeongsang National University, Jinju, Republic of Korea.

* These authors contributed equally to this work.

$\triangle$ Corresponding authors: June-Ho Byun (Department of Oral and Maxillofacial Surgery, Gyeongsang National University School of Medicine and Gyeongsang National University Hospital, Institute of Health Sciences, Gyeongsang National University, Chilam-dong, Jinju, Republic of Korea, Tel : 82-55-750-8258, Fax: 82-55-761-7024, E-mail address : surbyun@gnu.ac.kr) or Dong Kyun Woo (College of Pharmacy and Research Institute of Pharmaceutical Sciences, Gyeongsang National University, Jinju, Republic of Korea, Tel : 82-55-772-2428, E-mail address : dongkyun.woo@gnu.ac.kr )

(C) Ivyspring International Publisher. This is an open access article distributed under the terms of the Creative Commons Attribution (CC BY-NC) license (https://creativecommons.org/licenses/by-nc/4.0/). See http://ivyspring.com/terms for full terms and conditions.

Received: 2017.07.13; Accepted: 2017.10.11; Published: 2017.11.02

\begin{abstract}
Stem/progenitor cell-based regenerative medicine using the osteoblast differentiation of mesenchymal stem cells (MSCs) is regarded as a promising approach for the therapeutic treatment of various bone defects. The effects of the osteogenic differentiation of stem/progenitor cells on osteoclast differentiation may have important implications for use in therapy. However, there is little data regarding the expression of osteoclastogenic proteins during osteoblastic differentiation of human periosteum-derived cells (hPDCs) and whether factors expressed during this process can modulate osteoclastogenesis. In the present study, we measured expression of RANKL in hPDCs undergoing osteoblastic differentiation and found that expression of RANKL mRNA was markedly increased in these cells in a time-dependent manner. RANKL protein expression was also significantly enhanced in osteogenic-conditioned media from hPDCs undergoing osteoblastic differentiation. We then isolated and cultured CD34+ hematopoietic stem cells (HSCs) from umbilical cord blood (UCB) mononuclear cells (MNCs) and found that these cells were well differentiated into several hematopoietic lineages. Finally, we co-cultured human trabecular bone osteoblasts (hOBs) with CD34+ HSCs and used the conditioned medium, collected from hPDCs during osteoblastic differentiation, to investigate whether factors produced during osteoblast maturation can affect osteoclast differentiation. Specifically, we measured the effect of this osteogenic-conditioned media on expression of osteoclastogenic markers and osteoclast cell number. We found that osteoclastic marker gene expression was highest in co-cultures incubated with the conditioned medium collected from hPDCs with the greatest level of osteogenic maturation. Although further study will be needed to clarify the precise mechanisms that underlie osteogenic-conditioned medium-regulated osteoclastogenesis, our results suggest that the osteogenic maturation of hPDCs could promote osteoclastic potential
\end{abstract}

Key words: Periosteum-derived cells; Osteoblastic differentiation; Osteoclastic differentiation; Conditioned medium. 


\section{Introduction}

In recent years, substantial progress has been made towards developing stem/progenitor cell-based regenerative alternatives to autologous bone grafting for the treatment of various bone defects. Numerous studies have mainly focused on understanding the molecular biology of osteoblastogenesis, including osteoblastic preparation and the activity of appropriate stem/progenitor cells for use in therapy [1-3]. Because bone is a dynamic living tissue that undergoes continuous structural adaptation in response to the biological demands placed on it, as well as the fact that bone homeostasis depends on the resorption of bones by osteoclasts and the formation of bones by osteoblasts, the effects of osteogenic differentiation of stem/progenitor cells on osteoclastogenesis could also have important implications for the development of cell-based regenerative medicine.

During skeletal development and bone remodeling, osteoblasts directly interact with other cell types within bone, including osteocytes and hematopoietic stem cells (HSCs). Osteoblastic cells also play a critical role in the differentiation of bone-resorbing osteoclasts via the secretion of two cytokines that are required for this process, macrophage colony-stimulating factor (M-CSF) and receptor activator of nuclear factor-kappaB ligand (RANKL), which are also produced by neighboring stromal cells [4-6]. M-CSF is a secreted protein that acts through its receptor, colony-stimulating factor 1 receptor (CSF1R/c-FMS) on osteoclast precursor cells, leading to expression of receptor activator of NF- $\mathrm{kB}$ (RANK) and activation of the RANKL/RANK signaling pathways. RANKL is a type II homotrimeric transmembrane protein that is expressed as both a membrane-bound and secreted protein. The binding of this protein to osteoclast precursors occurs when HSCs progress through the colony forming unit for granulocytes and macrophages (CFU-GM) stage to become a colony forming unit for macrophages (CFU-M) before entering the osteoclast lineage. Binding of RANKL to RANK on CFU-M in the presence of M-CSF induces preosteoclast differentiation into a multinucleated cell that eventually becomes a mature osteoclast [7-10].

The periosteum contains multipotent cells with characteristics similar to those of bone marrow-derived mesenchymal stem cells (MSCs), which can differentiate into osteoblasts and chondrocytes. The use of human periosteum-derived cells (hPDCs) for bone tissue engineering in clinical settings has a significant advantage over current approaches. For example, the donor tissue is easily harvested, such as through the surgical extraction of an impacted third molar tooth. Our previous work has shown that cultured hPDCs differentiate into active osteoblastic cells that are involved in matrix mineralization $[11,12]$.

Although RANKL binds to RANK on cells derived from mononuclear precursors in the myeloid lineage and functions as a key factor for osteoclast differentiation and activation, RANKL produced by osteoblastic cells and osteoblast precursors could be an important source of RANK activation [13-15]. Further, to our knowledge, there is limited evidence regarding the effects of osteogenic-conditioned medium on osteoclastogenesis during the differentiation of cultured osteoprecursor cells. The purpose of this study was, therefore, to measure the expression of RANKL during osteogenic differentiation of hPDCs and to investigate the effect of osteogenic-conditioned media from hPDCs on osteoclastic differentiation.

\section{Materials and Methods}

\section{Culture of human periosteum-derived cells (hPDCs)}

Patients provided informed consent for collection of periosteal tissues, as required by the Ethics Committee of Gyeongsang National University Hospital (GNUH 2014-05-012). hPDCs were isolated as previously described technique [11,12]. Briefly, periosteal pieces were cultured at $37^{\circ} \mathrm{C}$, in $95 \%$ humidified air, and $5 \% \mathrm{CO}_{2}$, in $100-\mathrm{mm}$ culture dishes, containing Dulbecco's Modified Eagle's Medium (DMEM), supplemented with 10\% heat-inactivated fetal bovine serum (FBS), $100 \mathrm{IU} / \mathrm{mL}$ penicillin, and $100 \mu \mathrm{g} / \mathrm{mL}$ streptomycin. Upon reaching $90 \%$ confluence, adherent cells were passaged by gentle trypsinization and reseeded in fresh medium. The medium was changed every 3 days during the induction period.

\section{Analysis of surface markers}

Flow cytometry (FACSCalibur, Becton Dickinson, CA, USA) was used to detect hPDC surface antigens ( $10^{5}$ cells per marker). These cells were analyzed for the presence of the mesenchymal markers, CD44, CD73, CD105, and vimentin, and the absence of the hematopoietic markers, CD34 and CD45, as described previously [16]. Briefly, hPDCs at approximately $90 \%$ confluency were trypsinized and fixed in $3.7 \%$ formaldehyde solution. All antibodies were diluted (1:100) with $1 \%$ bovine serum albumin (BSA). Cells were labeled with FITC-conjugated 
anti-CD34, CD44, CD45, CD73, and vimentin at $4^{\circ} \mathrm{C}$ for $1 \mathrm{~h}$. Labeling with unconjugated anti-CD105 was performed at $4^{\circ} \mathrm{C}$ for $1 \mathrm{~h}$, followed by staining with FITC-conjugated secondary antibody at $4^{\circ} \mathrm{C}$ for $1 \mathrm{~h}$. HSCs surface markers were also analyzed using flow cytometry $\left(10^{5}\right.$ cells per marker). All antibodies were diluted (1:100) with 1\% BSA; labeling with FITC-conjugated anti-CD34, CD38, CD90, and PE-conjugated CD45RA was performed at $4^{\circ} \mathrm{C}$ for 1 $\mathrm{h}$ (Tables 1 and 2).

Table 1. Lists of flow cytometry antibodies used for evaluation of MSCs characterization in hPDCs

\begin{tabular}{lll}
\hline Antibody & Company & Amount \\
\hline $\begin{array}{l}\text { FITC mouse IgG, isotype } \\
\text { control }\end{array}$ & BD Pharmingen $^{\mathrm{TM}}$ & $0.5 \mathrm{mg} / \mathrm{ml}$ \\
$\begin{array}{l}\text { FITC mouse anti-human CD34 } \\
\text { FITC mouse anti-human CD45 }\end{array}$ & BD Pharmingen $^{\mathrm{TM}}$ & $0.5 \mathrm{mg} / \mathrm{ml}$ \\
FITC rat anti-mouse CD44 & BD Pharmingen ${ }^{\mathrm{TM}}$ & $0.5 \mathrm{mg} / \mathrm{ml}$ \\
$\begin{array}{l}\text { Mouse anti-human CD73 } \\
\text { Mouse monoclonal CD105 }\end{array}$ & BD Pharmingen & $0.5 \mathrm{mg} / \mathrm{ml}$ \\
$\begin{array}{l}\text { Mouse monoclonal } \\
\text { anti-vimentin }\end{array}$ & Santa Cruz biotechnology & $0.5 \mathrm{mg} / \mathrm{ml}$ \\
$\begin{array}{l}\text { FITC Goat anti-mouse IgG } \\
\text { Sigma-Aldrich }\end{array}$ & $0.5 \mathrm{mg} / \mathrm{ml}$ \\
& Santa Cruz biotechnology & $0.5 \mathrm{mg} / \mathrm{ml}$ \\
\hline
\end{tabular}

Table 2. Lists of flow cytometry antibodies used for characterization of HSCs

\begin{tabular}{lll}
\hline Antibody & Company & Amount \\
\hline FITC mouse IgG, isotype control & BD Pharmingen $^{\mathrm{TM}}$ & $0.5 \mathrm{mg} / \mathrm{ml}$ \\
FITC mouse anti-human CD34 & BD Pharmingen $^{\mathrm{TM}}$ & $0.5 \mathrm{mg} / \mathrm{ml}$ \\
FITC mouse anti-human CD90 & BD Pharmingen $^{\mathrm{TM}}$ & $0.5 \mathrm{mg} / \mathrm{ml}$ \\
FITC mouse anti-mouse CD38 & BD Pharmingen $^{\mathrm{TM}}$ & $0.5 \mathrm{mg} / \mathrm{ml}$ \\
PE mouse anti-human CD45RA & BD Pharmingen $^{\mathrm{TM}}$ & $0.5 \mathrm{mg} / \mathrm{ml}$ \\
FITC Goat anti-mouse IgG & Santa Cruz biotechnology $^{0}$ & $0.5 \mathrm{mg} / \mathrm{ml}$ \\
\hline
\end{tabular}

\section{In vitro mesenchymal lineage differentiation}

hPDCs at passage 3-5 were evaluated for their ability to differentiate into adipogenic, chondrogenic, or osteogenic lineages in vitro using previously described techniques [12,16]. Briefly, cells were cultured in lineage-specific media for 21 days, with the media changed every 3 days. Adipogenic medium contained $1 \mu \mathrm{M}$ dexamethasone, $10 \mu \mathrm{M}$ insulin, 100 $\mu \mathrm{M}$ indomethacin, and $500 \mu \mathrm{M}$ isobutylmethylxanthine. For the detection of lipid droplets, differentiated cells were stained by oil red $\mathrm{O}$ solution for $30 \mathrm{~min}$. Chondrogenic medium consisted of $\quad 90 \%$ StemPro Osteocyte/Chondrocyte Differentiation Basal Medium (Invitrogen, CA, USA) and $10 \%$ StemPro Chondrogenesis Supplement (Invitrogen). Chondrogenesis was evaluated by Alcian blue staining. Osteogenic induction medium was composed of DMEM, supplemented with $10 \%$ FBS, $50 \mu \mathrm{g} / \mathrm{mL}$-ascorbic acid 2-phosphate, $10 \mathrm{nM}$ dexamethasone, and $10 \mathrm{mM} \beta$-glycerophosphate. Osteogenesis was confirmed by alizarin red $S$ and von
Kossa staining. During osteoblastic differentiation, hPDCs were sampled and the culture media was collected $48 \mathrm{~h}$ after 0,10 , and 21 days of culture.

\section{Real-time quantitative polymerase chain reaction (qPCR) analysis}

Expression of osteoblast-specific genes and RANKL was analyzed by qPCR in hPDCs during osteoblastic differentiation at days 0,10 , and 21 of culture. In addition, the expression of osteoclast-related genes was analyzed in HSCs co-cultured with human trabecular bone osteoblasts (hOBs) by qPCR at day 21 of culture. These qPCR analyses were performed using a Rotor-Gene $Q$ cycler (QIAGEN, CA, USA), with 50 ng of cDNA, quantified with 2X Rotor-Gene SYBR Green Master Mix (QIAGEN), supplemented with specific primer sets (Table 3). Reactions were performed with an initial denaturation at $95^{\circ} \mathrm{C}$ for $10 \mathrm{~min}$, followed by 40 cycles of $95^{\circ} \mathrm{C}$ for $10 \mathrm{~s}, 60^{\circ} \mathrm{C}$ for $6 \mathrm{~s}$, and $72^{\circ} \mathrm{C}$ for $6 \mathrm{~s}$. Rotor-Gene Q Series Software (QIAGEN) was used to determine melting curves, amplification curves, and cycle threshold values (Ct values). Gene expression levels were normalized to the corresponding $\beta$-actin gene $(A C T B)$ value. All samples were run in triplicate and confirmed by $1.5 \%$ agarose gel electrophoresis.

Table 3. Primers used in $q P C R$

\begin{tabular}{|c|c|c|c|c|}
\hline & Target gene & Sequence & $\begin{array}{l}\text { Product } \\
\text { size (bp) }\end{array}$ & $\begin{array}{l}\text { Annealing } \\
\text { temperature }\end{array}$ \\
\hline & $\begin{array}{l}\text { Collagen } \\
\text { Type I }\end{array}$ & $\begin{array}{l}\text { F: TGAATACAAAACCACCAAGACC } \\
\text { R: GAGTTTACAGGAAGCAGACATG }\end{array}$ & 111 & $60^{\circ} \mathrm{C}$ \\
\hline & Runx2 & $\begin{array}{l}\text { F: CAAATCCTCCCCAAGTAGCT } \\
\text { R: ATACTGGGATGAGGAATGCG }\end{array}$ & 117 & $60^{\circ} \mathrm{C}$ \\
\hline 3 & Osteopontin & $\begin{array}{l}\text { F: TTGCAGCTTCTCAGCCAA } \\
\text { R: GGAGGCAAAAGCAAATCACCT }\end{array}$ & 132 & $60^{\circ} \mathrm{C}$ \\
\hline & Osteocalcin & $\begin{array}{l}\text { F: TCACACTCCTCGCCCTATTG } \\
\text { R: ACTTTTGCTGGACTCTGCAC }\end{array}$ & 89 & $60^{\circ} \mathrm{C}$ \\
\hline & RANKL & $\begin{array}{l}\text { F: GGCAGCACGCTATTAAATCC } \\
\text { R: GTCGCCAAACAGATTCATCC }\end{array}$ & 124 & $60^{\circ} \mathrm{C}$ \\
\hline & TRAP & $\begin{array}{l}\text { F: GATCCTGGGTGCAGACTTCA } \\
\text { R: GCGCTTGGAGATCTTAGAGT }\end{array}$ & 211 & $60^{\circ} \mathrm{C}$ \\
\hline & Cathepsin K & $\begin{array}{l}\text { F: ACCGGGGTATTGACTCTGAA } \\
\text { R: GAGTCAGGCTTGCATCAAT }\end{array}$ & 189 & $60^{\circ} \mathrm{C}$ \\
\hline & Integrin beta 3 & $\begin{array}{l}\text { F: TCGAGTTCCCAGTGAGTGAG } \\
\text { R: GACAGGTCCATCAAGTAGTAG }\end{array}$ & 202 & $60^{\circ} \mathrm{C}$ \\
\hline
\end{tabular}

\section{Detection of RANKL in} osteogenic-conditioned media by Enzyme-linked immunosorbent assay (ELISA)

During osteoblastic differentiation of hPDCs, culture media was collected after $48 \mathrm{~h}$ at 0,10 , and 21 days of culture, and RANKL levels were measured using the Human TRANCE/RANK L/TNFSF11 DuoSet ELISA Kit (R\&D Systems, MN, USA). In each case, $100 \mu \mathrm{l}$ of osteogenic-conditioned medium was assayed, as described in the manufacturer's manual. Optical density was read at a wavelength of $450 \mathrm{~nm}$ 
with a microplate reader (BioTek Instruments, VT, USA), and results were calculated using the standard curves generated from each assay.

\section{Isolation, culture and cryopreservation of CD34+ hematopoietic stem cells}

Sorting of HSCs was performed as previously described [12,17]. After obtaining the informed consent under approved medical guidelines set by Gyeongsang National University Hospital, human umbilical cords were obtained from full-term births, delivered by either caesarean section or normal vaginal delivery. Umbilical cord blood (UCB) samples were diluted 1:1 in Dulbecco's phosphate-buffered saline and overlaid onto Ficoll-Paque PLUS (GE Healthcare, CA, USA). Mononuclear cell (MNC) pellets were isolated by density gradient centrifugation at $400 \times \mathrm{g}$ for $30 \mathrm{~min}$ and treated with ammonium chloride $(160 \mathrm{mM})$ to lyse erythrocytes. Although it is well known that CD31, CD34, CD45, KDR, VE-cadherin, CD133, and von Willebrand factor are hematopoietic molecules, there is no single specific marker for HSCs. However, a characteristic feature of hematopoietic stem and progenitor cells is the presence of the CD34 antigen $[18,19]$. Here, in order to purify HSCs for characterization, we sorted CD34+ MNCs using the EasySep ${ }^{\mathrm{TM}}$ Human CD34 Positive Selection Kit (Stem Cell Technologies, Vancouver, Canada). Briefly, MNCs were re-suspended at $2 \times 10^{8}$ cells $/ \mathrm{mL}$ in 5 -mL tubes with $100 \mathrm{~mL}$ PBS containing 2\% FBS and $1 \mathrm{mM}$ EDTA, to remove free $\mathrm{Ca}^{+2}$ and $\mathrm{Mg}^{+2}$, and the EasySep ${ }^{\mathrm{TM}}$ Human CD34 Positive Selection Cocktail; cells were incubated at room temperature for $15 \mathrm{~min}$. The EasySep $^{\mathrm{TM}}$ Magnetic Nanoparticles were added at a concentration of $50 \mathrm{~mL} / \mathrm{mL}$ of cells, and the solution was incubated at room temperature for $10 \mathrm{~min}$. The tube was then placed into the EasySep ${ }^{\mathrm{TM}}$ magnet for 5 min, and the supernatant fraction was decanted. The tube was removed from the magnet, and $2.5 \mathrm{~mL}$ of the medium was added. The cells were mixed, and the tube was placed back into the magnet for $5 \mathrm{~min}$. The supernatant fraction was removed again, with the magnetically labeled cells remaining inside the tube [20].

CD34+ cells were cultured in StemPro®-34 SFM medium (Invitrogen) containing $2 \mathrm{mM}$ L-glutamine, $100 \mathrm{ng} / \mathrm{mL}$ recombinant human stem cell factor (SCF), $50 \mathrm{ng} / \mathrm{mL}$ recombinant human interleukin-3 (IL-3), and $25 \mathrm{ng} / \mathrm{mL}$ recombinant human granulocyte-macrophage colony-stimulating factor (GM-CSF) in 24 well plates $\left(2 \times 10^{3}\right.$ cells per $\mathrm{mL}$ of media). Upon reaching a cell concentration of $10^{5}$ cells $/ \mathrm{mL}$, the media was replaced with fresh media. CD34+ cells were cryopreserved using four-step cryopreservation protocols [21, 22]. Briefly, the cells were frozen to $0^{\circ} \mathrm{C}$ in $5 \%$ dimethyl sulfoxide (DMSO) and DMEM (10\% FBS) at a rate of $5^{\circ} \mathrm{C} / \mathrm{min}$ and equilibrated for $5 \mathrm{~min}$. The cells were then frozen to $-45^{\circ} \mathrm{C}$ at a rate of $1^{\circ} \mathrm{C} / \mathrm{min}$ and then to $-70^{\circ} \mathrm{C}$ at a rate of $5^{\circ} \mathrm{C} / \mathrm{min}$ for $5 \mathrm{~min}$.

\section{Colony forming unit (CFU) assay}

CD34+ HSCs were evaluated for their ability of to proliferate and differentiate into colonies in a semi-solid medium using a CFU assay. CD34+ hematopoietic colonies were demonstrated by growing cells in MethoCult ${ }^{\mathrm{TM}}$ media (Stem Cell Technologies), which supports optimal growth of different types of progenitors (e.g., burst-forming unit-erythroid [BFU-E], colony forming unit-erythroid [CFU-E], colony forming unit-granulocyte, macrophage [CFU-GM], and colony forming unit-granulocyte, erythroid, macrophage, megakaryocyte [CFU-GEMM]). Briefly, the cells were diluted with Iscove's Modified Dulbecco's Medium with 2\% FBS and mixed with MethoCult ${ }^{\mathrm{TM}}$ media, containing methylcellulose, recombinant human SCF, recombinant human GM-CSF, recombinant human IL-3, and recombinant human erythropoietin (EFO). Cells were then seeded into $35-\mathrm{mm}$ culture dishes at a density of $5 \times 10^{3}$ cells/dish, with a sterile 16 gauge blunt-end needle. These were cultured for 14 days at $37^{\circ} \mathrm{C}$ in a $95 \%$ humidified atmosphere with $5 \% \mathrm{CO}_{2}$, at which point colony morphology was examined.

\section{Culture of human osteoblasts (hOBs) from trabecular bone}

Isolation and culture of hOBs was performed as previously described [23, 24]. Trabecular bone samples were harvested from the mandible during surgical extraction of lower impacted third molar teeth from patients who had provided informed consent, as required by the Ethics Committee of Gyeongsang National University Hospital. Human trabecular bone particles were cultured in Minimum Essential Medium Eagle - alpha modification (a-MEM), containing 10\% FBS, $2 \mathrm{mM}$ L-glutamine, and $100 \mu \mathrm{M}$ L-ascorbate-2 phosphate in $35 \mathrm{~mm}$ dishes. This allows osteoblastic cells to migrate from the fragments and proliferate. The medium was changed every 3 days during culture.

\section{Effect of osteogenic-conditioned medium on expression of osteoclastogenic markers and osteoclast number during osteoclast differentiation}

CD34+ cells and hOBs were co-cultured to promote osteoclast differentiation in a-MEM, containing $1 \% \mathrm{BSA}$, transferrin $(100 \mathrm{mg} / \mathrm{mL})$, insulin 
(10 mg/mL), human low-density lipoprotein (LDL, 20 $\mathrm{mg} / \mathrm{mL})$, L-ascorbate-2-phosphate $(100 \mathrm{mM})$, platelet-derived growth factor (PDGF)-BB (10 nM), DEX (10 nM), L-glutamine (2 mM), 1,25D (20 nM), and recombinant human M-CSF (25 ng/mL) [25-27]. Cultures were maintained for 21 days, and cells were co-cultured under four different conditions: (i) a-MEM, (ii) a-MEM + osteogenic-conditioned media from hPDCs collected $48 \mathrm{~h}$ after day 0 of culture (a-MEM + day 0-osteogenic CM), (iii) a-MEM + osteogenic-conditioned media from hPDCs collected $48 \mathrm{~h}$ after day 10 of culture (a-MEM + day 10-osteogenic CM), (iv) and a-MEM + osteogenic-conditioned media from hPDCs collected $48 \mathrm{~h}$ after day 21 of culture (a-MEM + day 21-osteogenic $\mathrm{CM}$ ). Each osteogenic-conditioned media was used at a 1:1 ratio with a-MEM.

Because osteoclast precursor cells of the monocyte-macrophage lineage fuse to form tartrate-resistant acid phosphatase (TRAP)-positive multinucleated cells, osteoclast differentiation and osteoclast number were examined at day 21 of culture using a TRAP staining kit (Sigma-Aldrich, MO, USA), according to the manufacturer's instructions $[28,29]$. The cells were incubated in fixation solution for $5 \mathrm{~min}$ at room temperature and washed three times with deionized water. Fixed cells were then stained with TRAP staining solution for $1 \mathrm{~h}$ at $37^{\circ}$ C. TRAP-positive multinucleated cells with more than three nuclei, as determined by light microscopy (Zeiss Axiostar Plus, Jena, Germany), were counted as osteoclasts. Expression of marker genes involved in osteoclastogenesis (TRAP, cathepsin $\mathrm{K}$, and integrin beta-3) was measured by qPCR at day 21 of co-culture.

\section{Statistical analysis}

Each experiment was performed independently at least three times, and in all cases, results from one experimental replicate are shown as representative data. Data are expressed as mean \pm standard error of the mean (SEM), and statistical analyses were computed using SPSS Statistics 23.0 software (IBM corp., NY, USA). Data were evaluated using one-way analysis of variance (ANOVA), with Tukey's multiple comparison and the Mann-Whitney test. Comparisons with $P<0.05$ were considered statistically significant.

\section{Results}

\section{Characterization of hPDCs}

Flow cytometric analysis of cell surface antigens on hPDCs isolated from periosteal tissues revealed that these cells are positive for the mesenchymal markers, CD44, CD73, CD105, and vimentin, and are negative for the hematopoietic stem cell markers, CD34 and CD45 (Fig. 1A). These hPDCs were cultured in different induction media, and cytochemical staining further confirmed that they can be successfully differentiated into various mesenchymal lineages, including adipocytes, osteocytes, and chondrocytes, as confirmed by the accumulation of lipid vacuoles and intracellular lipid droplets, the deposition of mineralized extracellular matrix, and the presence of sulfated proteoglycans, respectively (Fig. 1C). These results suggest that hPDCs are phenotypically similar to MSCs.

\section{Expression of osteoblast-specific genes and RANKL in hPDCs undergoing osteoblastic differentiation}

During osteoblastic differentiation of hPDCs in osteogenic induction medium, expression of the osteoblast-specific genes, runt-related transcription factor 2 (Runx2), collagen type I, osteocalcin, and osteopontin, as well as that of RANKL, was evaluated by qPCR (Fig. 2A and B). We observed that after culturing for 10 days, both Runx 2 and collagen type I expression was notably increased in differentiating hPDCs, after which their expression significantly decreased. Conversely, expression of both osteocalcin and osteopontin was markedly increased over the entire 21-day course of the experiment in a time-dependent manner. Moreover, we also observed a time-dependent increase in RANKL mRNA expression in periosteum-derived osteoblastic cells throughout the 3-week experimental duration. In addition, levels of RANKL protein were found to be increased in osteogenic-conditioned media collected from hPDCs during osteoblastic differentiation (Fig. 2C). RANKL levels were highest in osteogenic-conditioned media obtained from hPDCs at day 21 of culture, whereas they were lowest in osteogenic-conditioned media obtained from the cells at day 0 of culture (Fig. 2C).

Alkaline phosphatase (ALP) and collagen type I are early markers of osteoblast differentiation, whereas osteocalcin and osteopontin, which are related to matrix mineralization, are associated with the endpoint of full maturation of the osteoblast phenotype. Additionally, RANKL is the most important cytokine for osteoclast differentiation and activity. Therefore, our results suggest that the activity of osteoclast-related genes could be also enhanced during osteoblastic maturation of hPDCs.

\section{Characterization of CD34+ HSCs}

We next isolated CD34+ HSCs from MNCs obtained from UCB samples by positive selection. These CD34+ HSCs were observed to display a 
rounded morphology (Fig. 3A) and were non-adherent to culture dishes. Notably, $<95 \%$ of cells expressed CD34 immediately after sorting, however, they showed $>95 \%$ CD34 positivity, and no expression of negative markers (CD45RA, CD38), after replating (Fig. 3B). These CD34+ cells were further capable of being induced and differentiated into hematopoietic lineages (Fig. 3C). BFU-E was represented by a large, red, hemoglobinized colony, containing numerous erythroid progenitors, whereas a small, red, hemoglobinized colony, containing several clusters with few erythroblasts, was observed for CFU-E. CFU-GM formed a colony with a heterogeneous population of macrophages and granulocytes; however, it did not appear red and hemoglobinized. A large colony of multi-lineage progenitors was observed for CFU-GEMM. Some cells were red and hemoglobinized, however, others within the CFU-GEMM culture were not (Fig. 3C). Based on these results, we refer to the sorted CD34+ cells as human umbilical cord blood-derived CD34+ HSCs.

\section{Isolation and culture of hOBs from trabecular bone}

We next isolated and cultured hOBs from mandibular trabecular bone tissue. When trabecular bony particles were placed in medium, cells migrating from these samples appeared after approximately 12-14 days. With continued incubation, the cells formed a semi-confluent monolayer after approximately 26-28 days. These semi-confluent cultures of hOBs were digested with dispase/collagenase/trypsin, and single cell suspensions were collected (Fig. 4).

\section{Effect of osteogenic-conditioned medium on expression of osteoclastogenic markers and osteoclast number during osteoclast differentiation}

To test the effect of osteogenic-conditioned media on osteoclast differentiation, we measured expression of osteoclastogenic markers, TRAP, cathepsin $\mathrm{K}$, and integrin beta-3, in co-cultures of hOBs and CD34+ HSCs incubated in four different media conditions: (i) a-MEM, (ii) a-MEM + day 0-osteogenic CM, (iii) a-MEM + day 10-osteogenic $\mathrm{CM}$, and (iv) a-MEM + day 21-osteogenic CM after 21 days. We observed no difference in osteoclastogenic gene expression between the a-MEM and the a-MEM + day 0-osteogenic CM group. However, marker expression was significantly higher in the a-MEM + day 10-osteogenic CM group and the a-MEM + day 21-osteogenic CM group, than in the a-MEM or
a-MEM + day 0-osteogenic CM. Overall, expression of osteoclastogenesis markers was found to be highest in the a-MEM + day 21-osteogenic CM group.

After osteoclast differentiation in each four different media conditions, the number of osteoclasts was evaluated by TRAP staining of the co-cultured cells. Consistent with our analysis of osteoclastogenic marker expression, osteoclast number was highest higher in co-cultured cells incubated with a-MEM + day 21-osteogenic CM. However, there was no clear difference in the osteoclast number among other media groups (Fig. 5). These results suggest that osteoblastic induction of hPDCs may have the ability to drive osteoclast differentiation.

\section{Discussion}

Biological bone grafts (autograft, allograft, and xenograft) are commonly used for the treatment of critical-sized bone defects in the clinical setting. However, a shortage of available grafts, in combination with donor site complications (i.e., the necessity for an additional painful procedure, infection, and nerve damage, in the case of autografts, and poor integration with host bone, toxicity, and risk of disease transmission/immune rejection, in the case of allografts and xenografts), limits the ability of current practices to meet clinical needs. In recent years, stem/progenitor cell-based regenerative medicine has emerged as a promising approach for the therapeutic treatment of bone defects. In particular, many studies have focused on the in vitro osteoblast differentiation capability of stem/progenitor cells harvested from various sources in the human body. However, because both bone formation and bone resorption are physiologically controlled by osteoclastic resorption and synthesis of bone matrix by osteoblasts, osteoclasts also play a crucial role in the bone regeneration process $[4-6,30]$.

Osteoclasts are multinucleated cells that arise from the fusion of myeloid hematopoietic precursors formed in the bone marrow. Although chemokines and cytokines, such as M-CSF and RANKL, are required for osteoclast differentiation in normal and pathologic bone remodeling, the major sources of RANKL production are bone marrow stromal cells, osteoblasts, and mesenchymal cells of the periosteum in the bone or bone marrow environment $[8,10]$. In this study, we examined the effect of conditioned medium, obtained from osteoblastic cultures of hPDCs, on osteoclast differentiation. In addition, we measured the expression of RANKL at both the mRNA and protein level during osteoblast differentiation of hPDCs. 
A
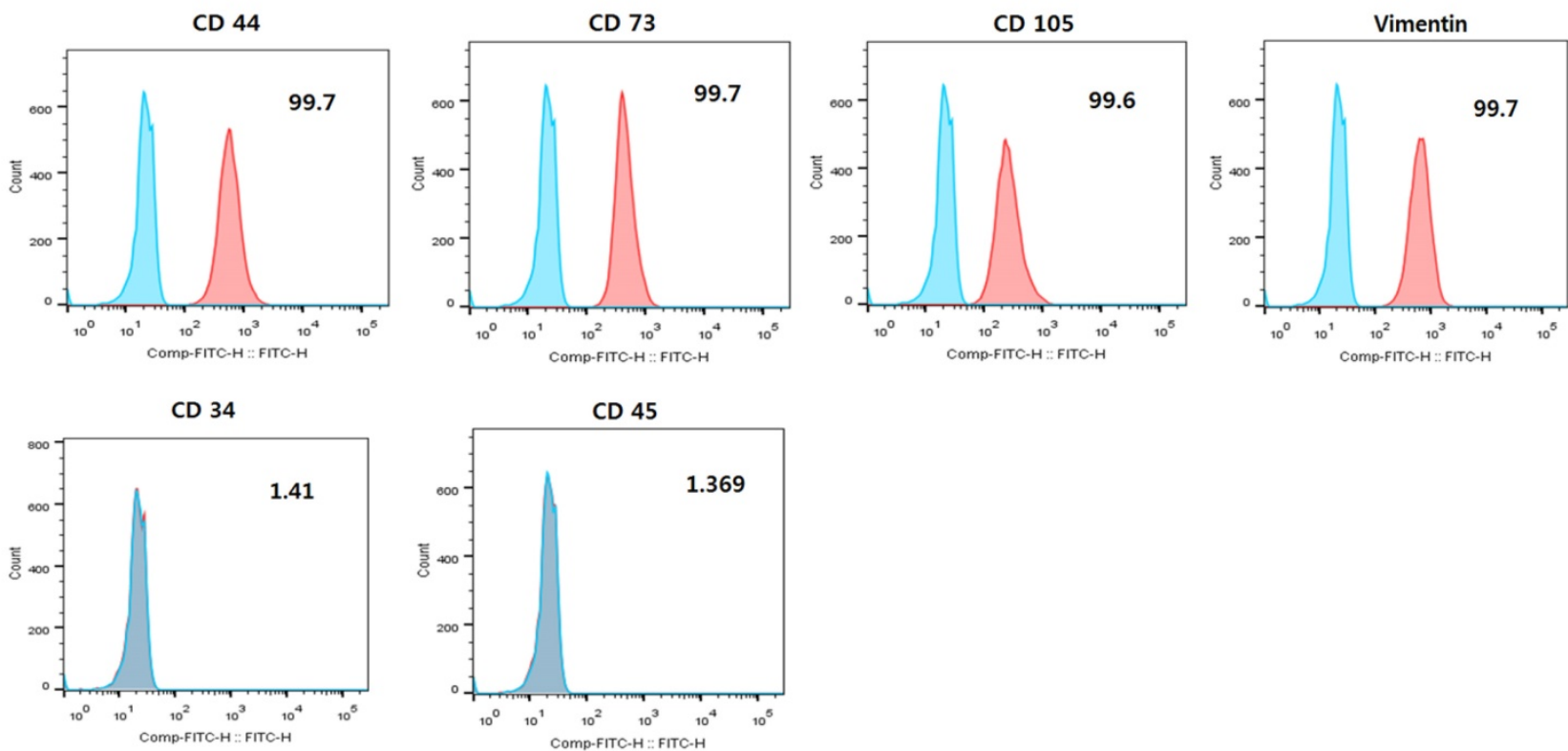

B

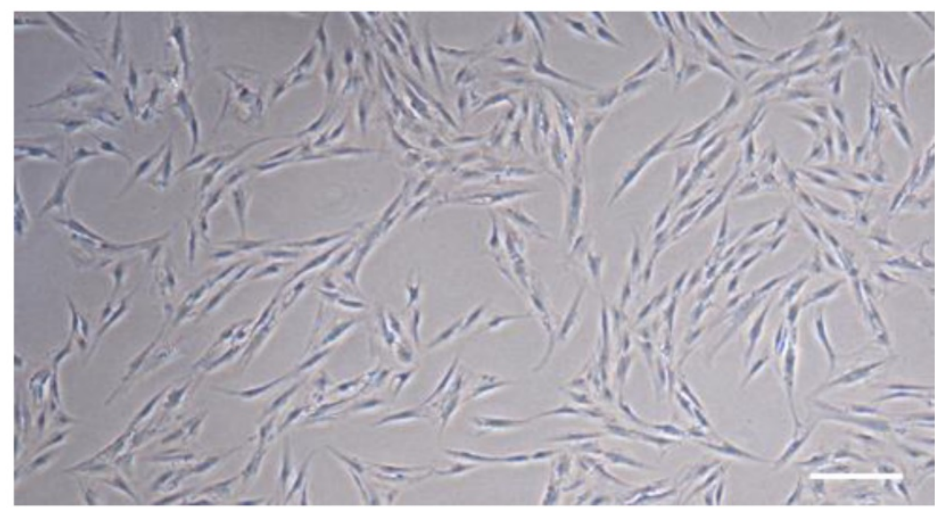

C

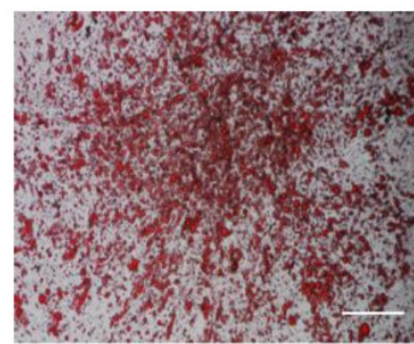

Oil red 0

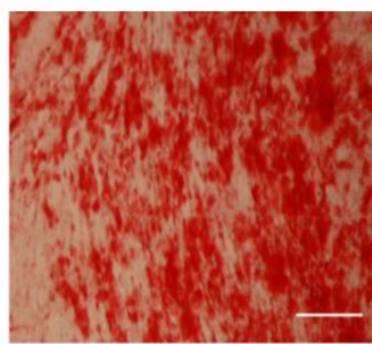

Alizarin red $\mathrm{S}$

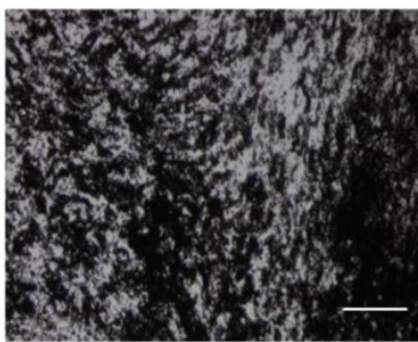

Von kossa

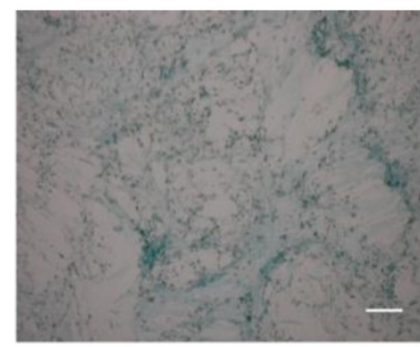

Alcan blue

Figure 1. Characterization of hPDCs. A: hPDCs are positive for surface markers present on MSCs. B: Differential interference contrast (DIC) microscope image of hPDCs at passage four reveals a fibroblast-like morphology; scale bar $=250 \mu \mathrm{m}$. C: In vitro lineage differentiation potential of hPDCs. Adipogenesis was demonstrated by oil red $\mathrm{O}$ staining of lipid droplets. Osteogenesis was confirmed by alizarin red $\mathrm{S}$ and von Kossa staining of mineralized nodules and calcium deposition. Chondrogenesis was detected by Alcian blue staining of proteoglycan synthesis. Scale bar $=100 \mu \mathrm{m}$. 
The periosteum contains multipotent cells with characteristics similar to those of bone marrow-derived MSCs, which can differentiate into osteoblasts and chondrocytes. Here, we found that hPDCs were positive for markers present in mesenchymal cells (CD44, CD73, CD105, and vimentin). Moreover, these cells were successfully differentiated into three different mesenchymal lineages, adipocytes, osteocytes, and chondrocytes, and thus can be classified as human periosteum-derived MSCs.

A

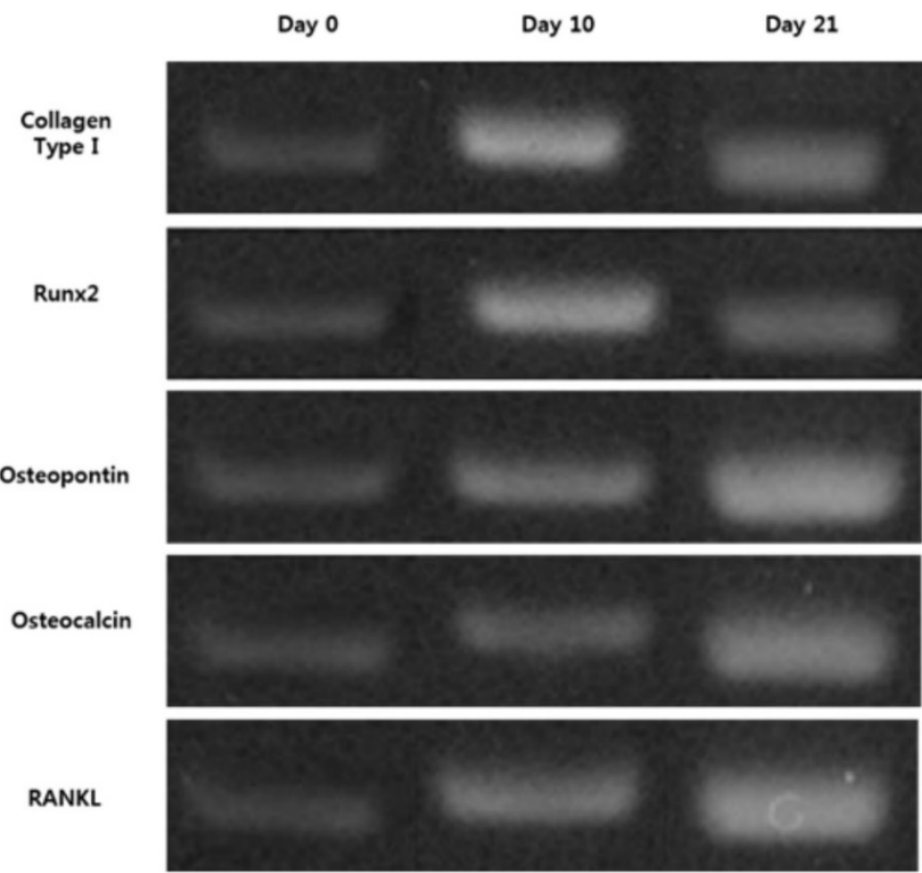

B
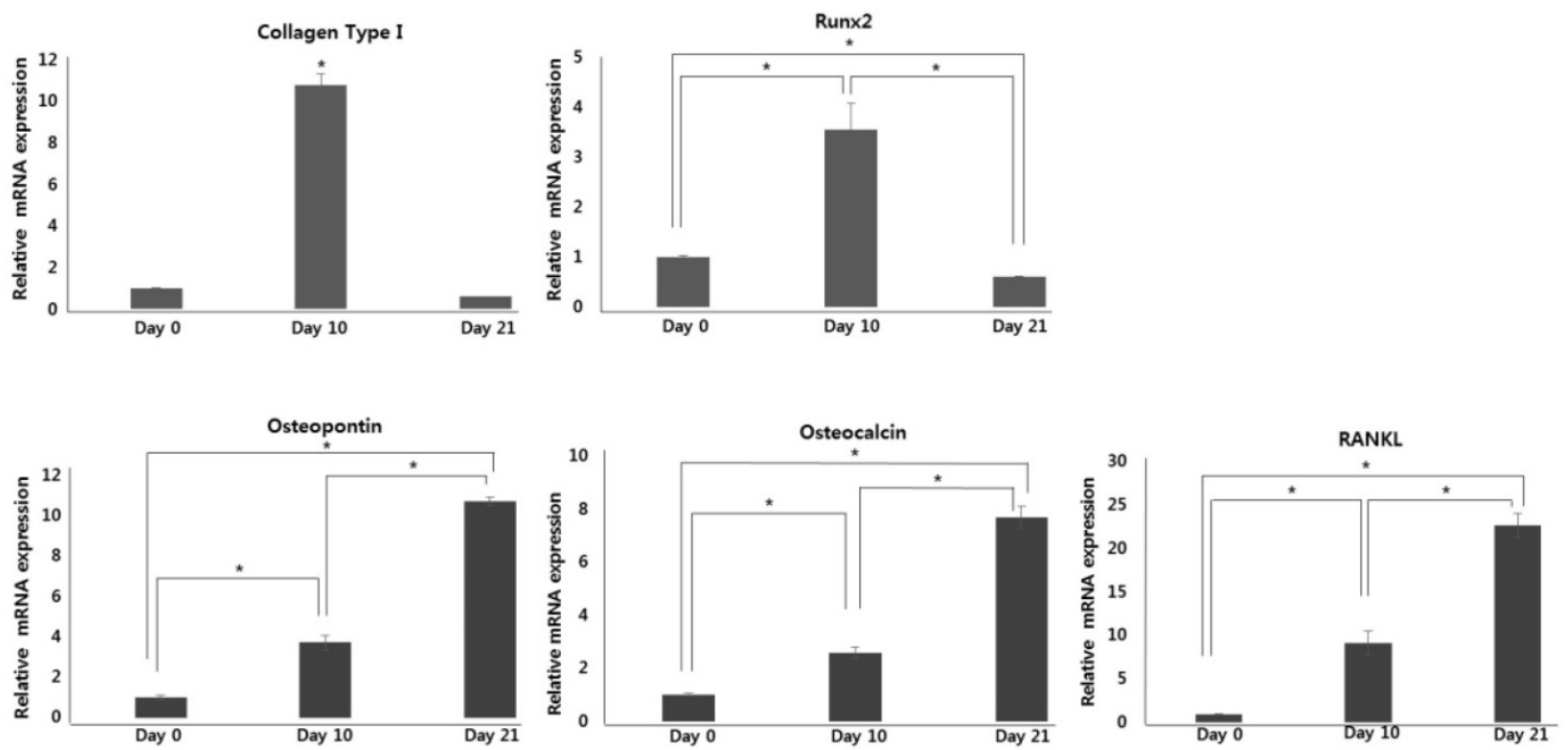
C

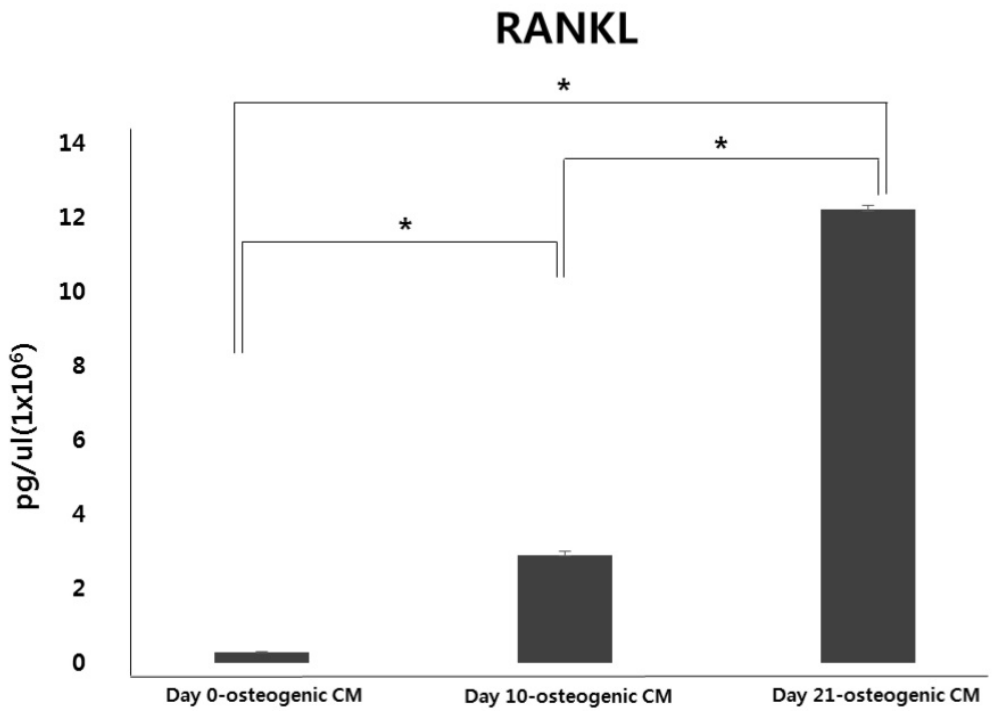

Figure 2. Expression of osteoblast-specific genes and RANKL during osteoblastic differentiation of $h P D C s$. Values are mean $\pm S E M$ ( $n=3$ ). A and B: Expression of collagen type I and Runx 2 was significantly increased in the hPDCs at day 10 of culture, but was markedly decreased at the 21-day time point. Conversely, expression of osteocalcin, osteopontin, and RANKL mRNA increased in a time-dependent manner up to day 21 of culture. C: Levels of RANKL protein also increased over the 3-week experimental duration and were highest in osteogenic-conditioned media collected from hPDCs at day 21 of culture.

To our knowledge, there is limited experimental data regarding the expression of osteoclastic factors, including RANKL, during osteoblast differentiation of hPDCs. In our analyses, we found that expression of RANKL was upregulated during osteoblastic differentiation of hPDCs, in a time-dependent manner. Furthermore, concomitant with osteoblastic maturation, RANKL protein levels were also significantly increased in osteogenic-conditioned media collected from hPDCs. In previous studies, RANKL production was found to be highest in undifferentiated stromal cells and is greatly reduced once these multipotent mesenchymal cells become terminally committed to the osteoblastic phenotype $[31,32]$. Further study is therefore needed to elucidate the relationship between RANKL expression level and differentiation of human periosteum-derived osteoblasts.

Human UCB contains a large number of HSCs that can be cryopreserved for later use in transplantation. Cord blood-derived HSCs have several advantages over adult peripheral blood-derived progenitors or bone marrow-derived HSCs, including the capacity to form a greater number of colonies, a higher rate of proliferation, and longer telomeres. Transplantation of cord blood also carries a lower risk of graft-versus-host disease than bone marrow transplantation. Although several factors are markers for hematopoietic stem cells, there is no single specific marker to distinguish HSCs from the other cells. In this study, we used positive selection for CD34 to isolate HSCs from cord blood
MNCs for further characterization. CD34 is a glycosylated type I transmembrane protein expressed on early lympho-hematopoietic stem and progenitors, small-vessel endothelial cells, embryonic fibroblasts, and fibroblast-like dendritic cells in connective tissues. In addition, most in vivo studies of HSCs in vasculogenesis have utilized HSCs differentiated from CD34+ mononuclear cells. Although the precise function of CD34 is still unknown, its expression pattern suggests a significant role in early hematopoiesis [12, 18, 19, 33-35]. Here, we found that UCB CD34+ cells were well differentiated into hematopoietic lineages (BFU-E, CFU-E, CFU-GM, and CFU-GEMM), and therefore, these can be considered to be human umbilical cord blood-derived CD34+ HSCs.

Using these CD34+ UCB-derived MSCs, we established co-cultures with hOBs to measure the effect of osteogenic-conditioned medium from hPDCs on the expression of osteoclastogenic markers. Remarkably, we found that expression of osteoclastogenesis genes was highest in co-cultures containing osteogenic-conditioned medium from hPDCs with the highest degree of osteoblastic differentiation. Although the precise mechanism by which osteogenic-conditioned medium from hPDCs stimulates osteoclastogenesis is not fully clarified and will require further study, the primary findings of this study indicate that the osteoblastic maturation of hPDCs may have the ability to enhance osteoclast differentiation. 
A
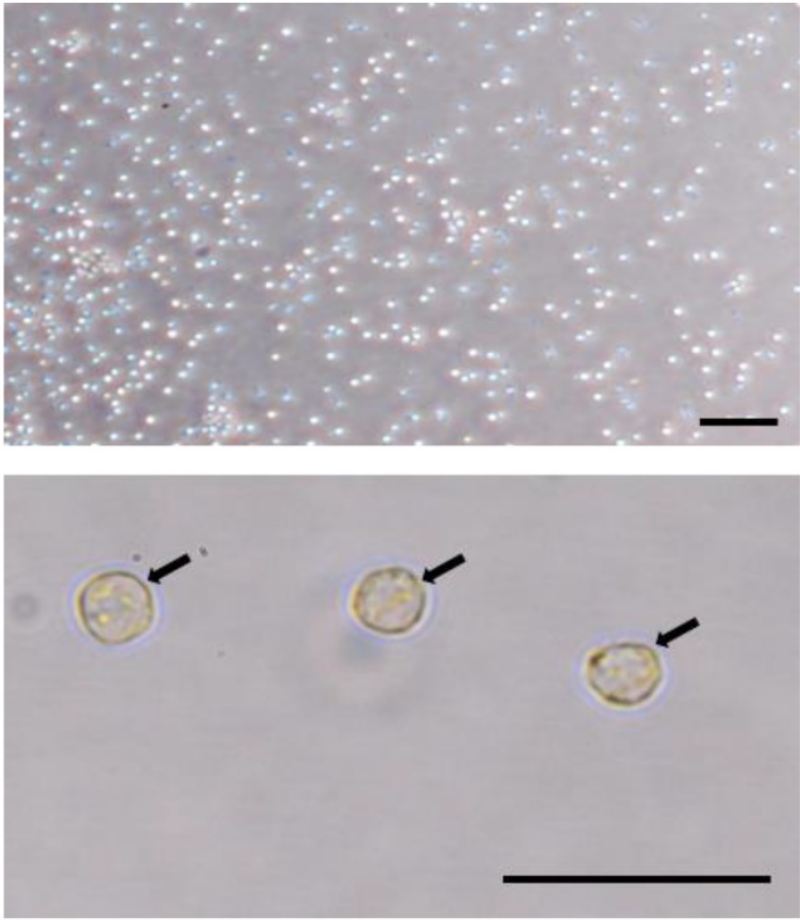

B
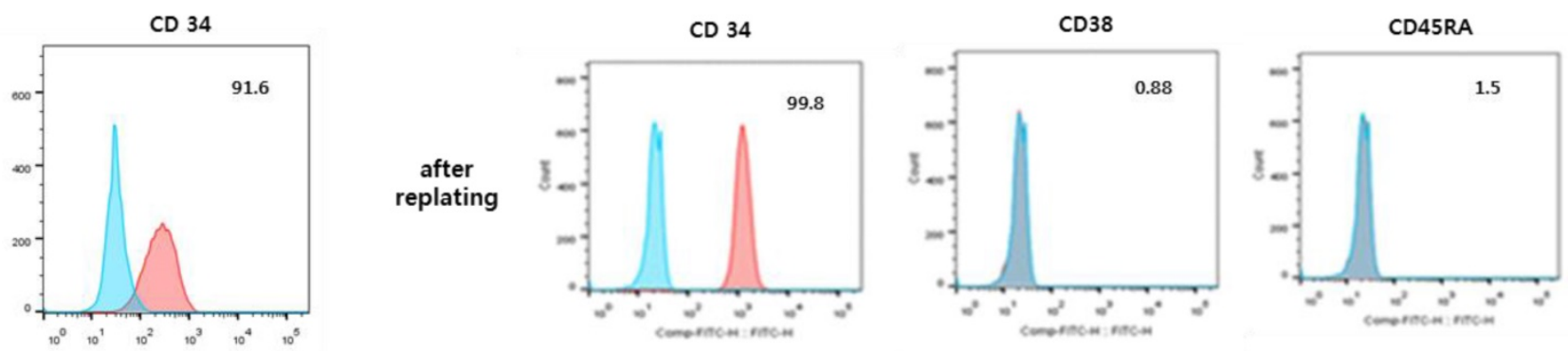

C

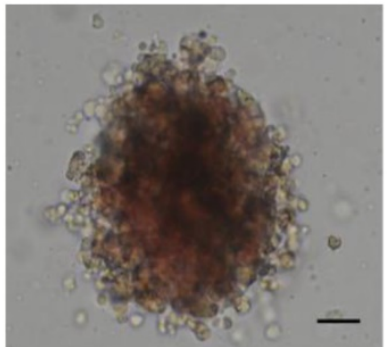

BFU-E

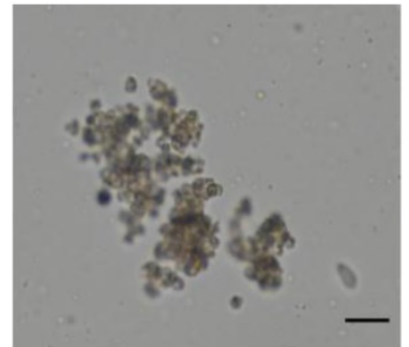

CFU-E

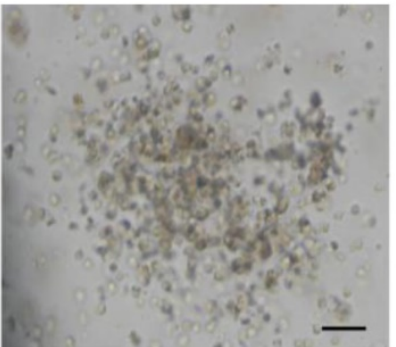

CFU-GM

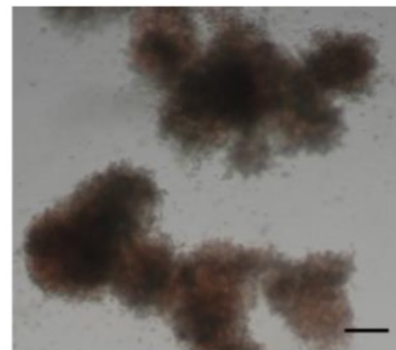

CFU-GEMM

Figure 3. Characterization of CD34+ HSCs. A: CD34+ HSCs display a round morphology. Scale bar $=50 \mu \mathrm{m}$. B: Expression of the hematopoietic marker (CD34+) was more obvious in the CD34+ HSCs after replating. C: CD34+ HSCs were able to be differentiated into hematopoietic lineages (BFU-E, CFU-E, CFU-GM, and CFU-GEMM). 

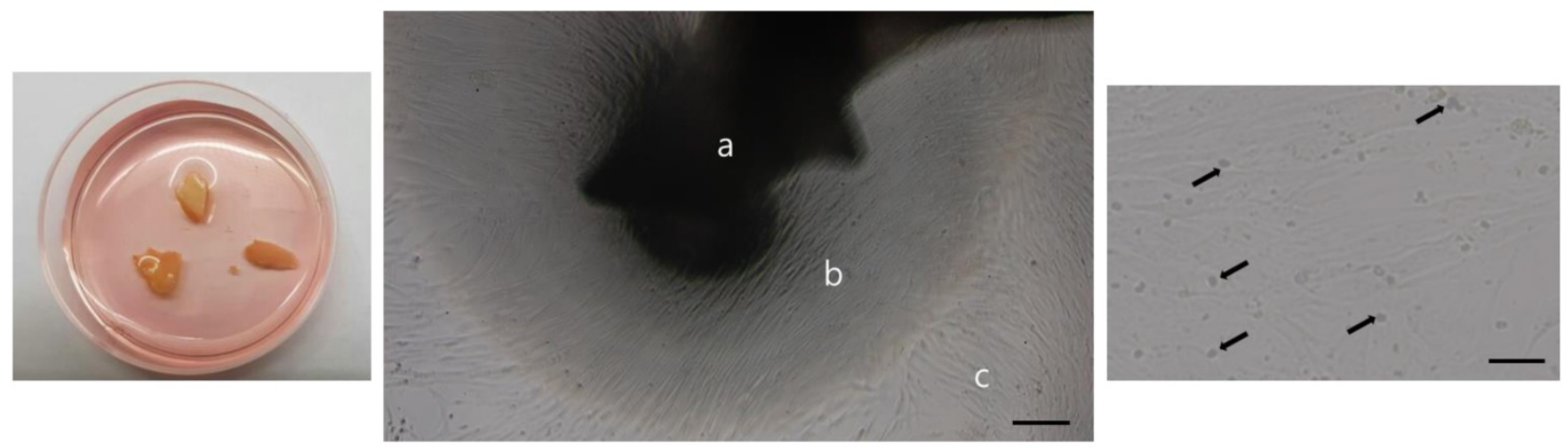

Figure 4. Osteoblasts were isolated and cultured from human trabecular bone. A: trabecular bone fragment, B: isolated osteoblasts, and C: migrated osteoblasts. Black arrows indicate the precipitates regarded as mineralized matrix formation. Scale bar $=100 \mu \mathrm{m}$.

A
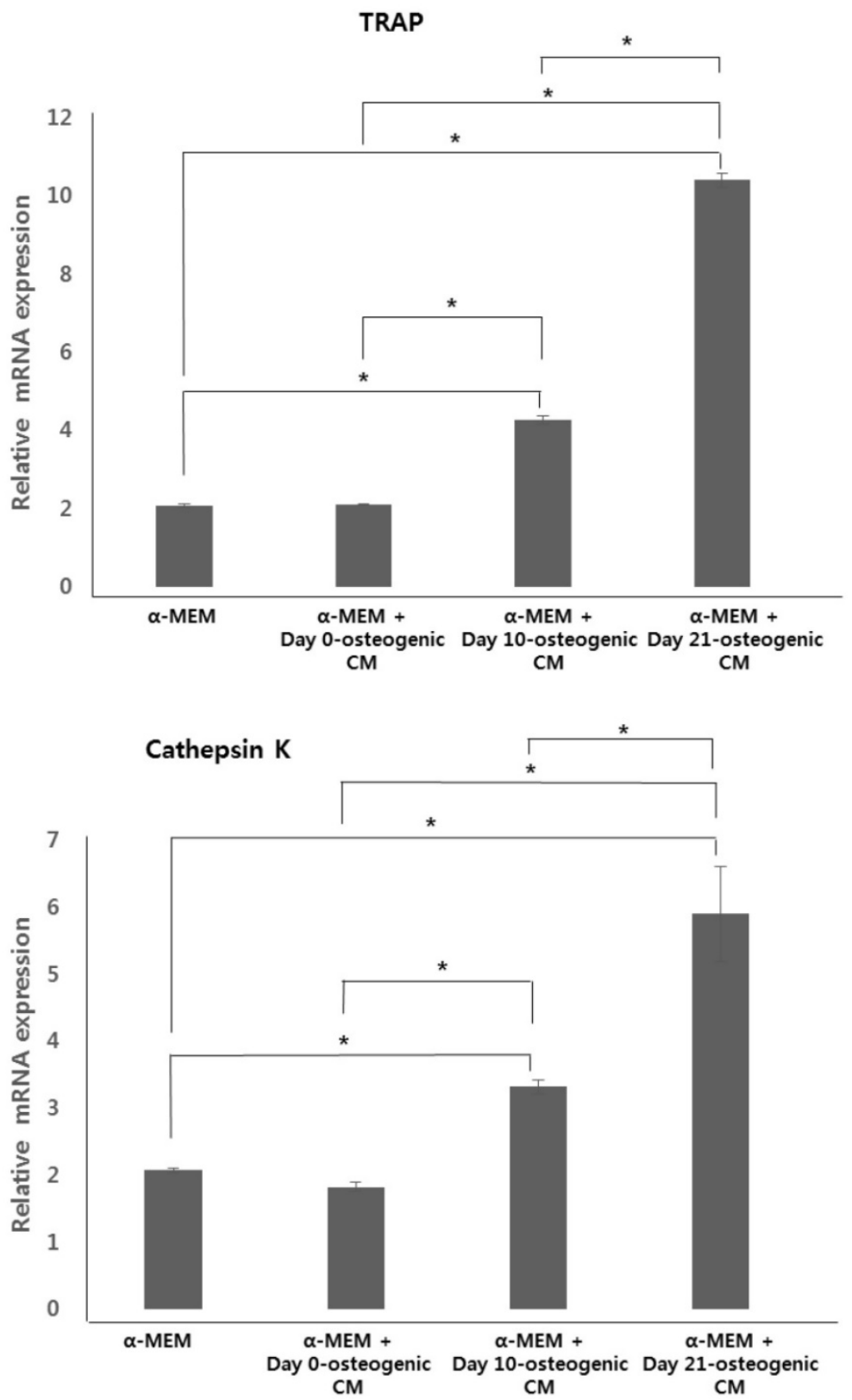


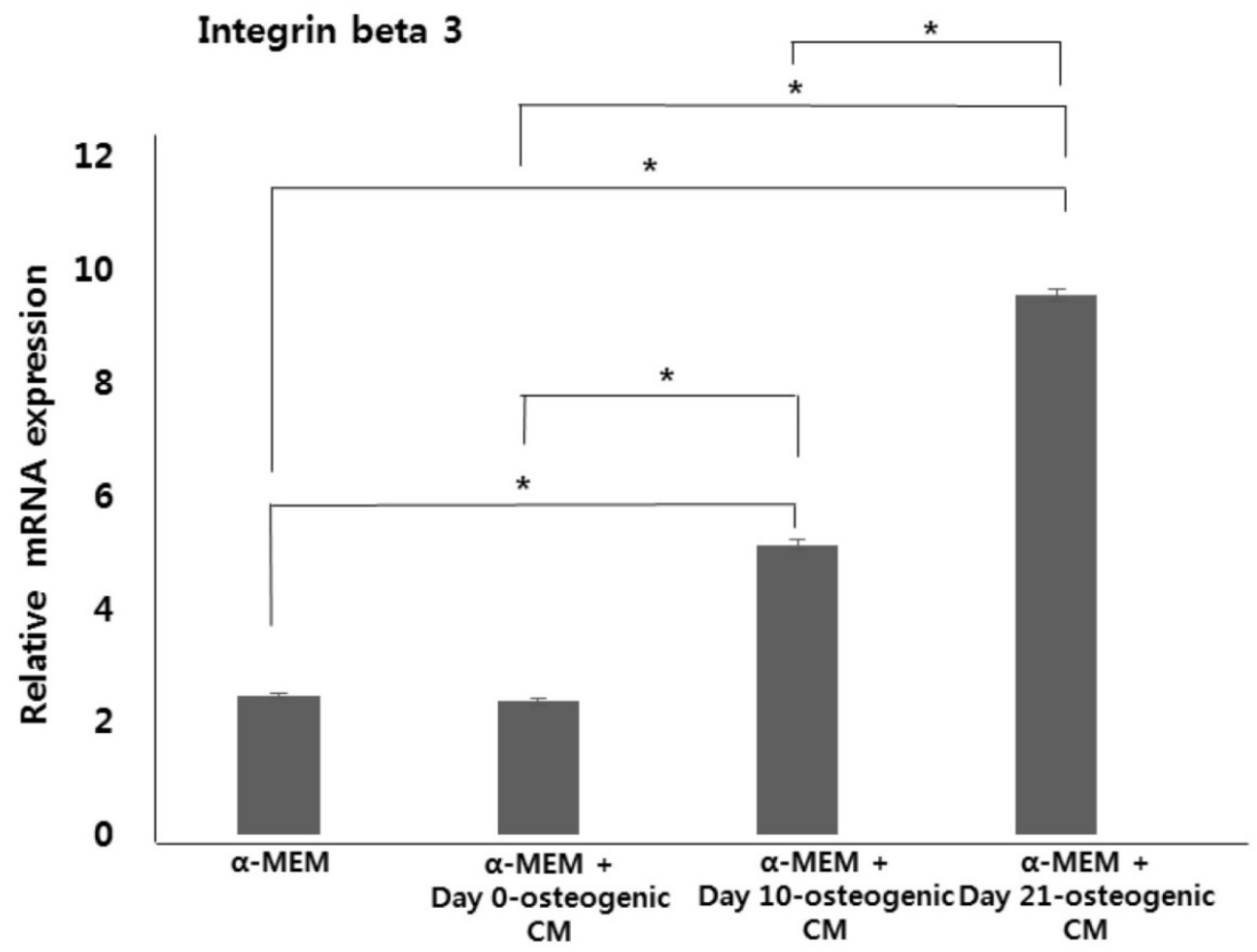

B
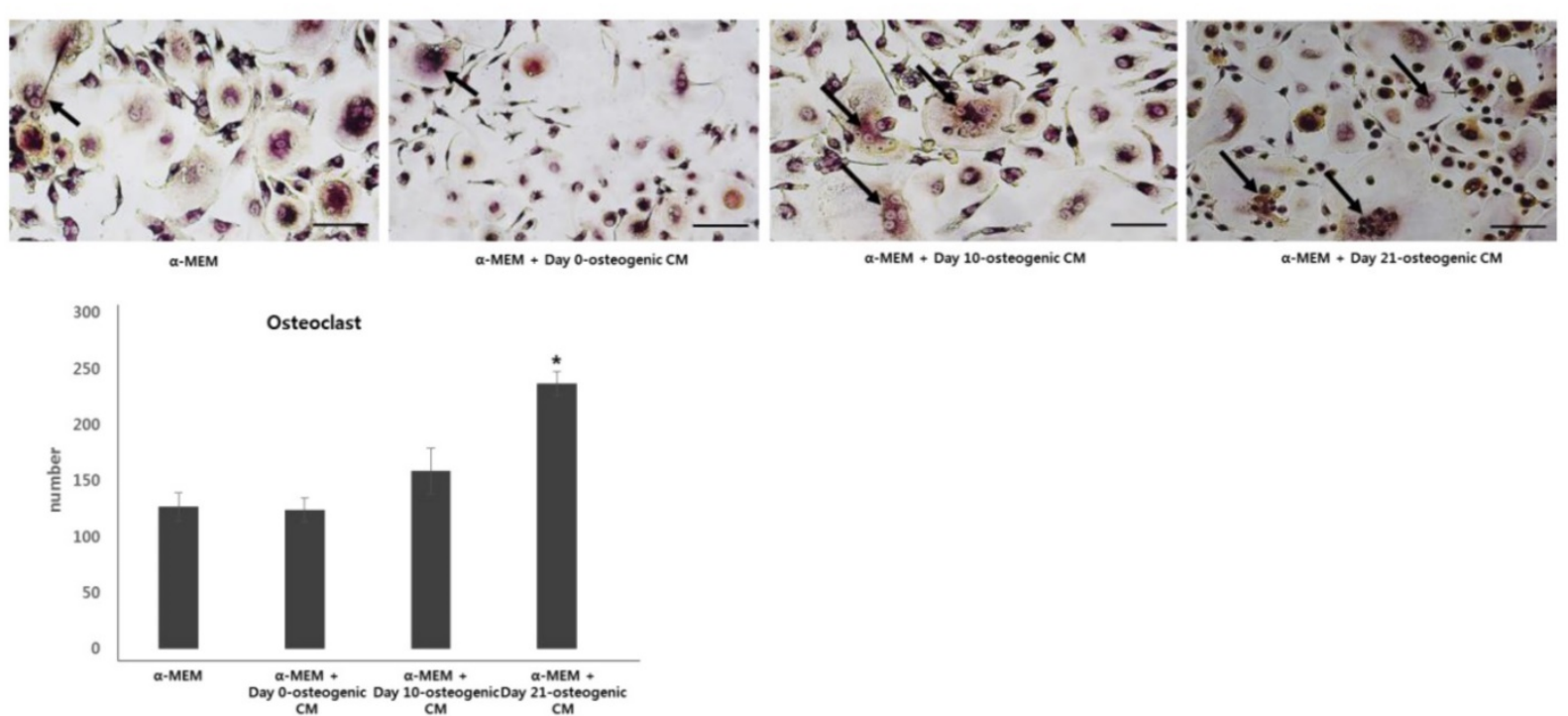

Figure 5. Expression of osteoclastogenic markers and osteoclast number. hOBs were co-cultured with CD34+ HSCs and osteogenic-conditioned medium from hPDCs undergoing osteoblastic differentiation (collected $48 \mathrm{~h}$ after 0,10 , and 21 days of culture). A: Expression of osteoclastogenesis markers, TRAP, cathepsin K, and integrin beta-3, was the markedly higher in $\alpha-M E M+$ day 21 -osteogenic CM group. B: Osteoclast number, indicated by TRAP staining, was significantly increased in the $\alpha-M E M+$ day 21 -osteogenic CM group. Scale bar $=250 \mu \mathrm{m}$.

\section{Acknowledgements}

This research was supported by Basic Science Research Program through the National Research Foundation of Korea (NRF) funded by the Ministry of Education, Science and Technology (2015R1A5A2008833，2016R1D1A1B03932437). This study was also supported by a grant of the Korean Health Technology R\&D Project, Ministry of Health \& Welfare, Republic of Korea (HI13C1596, HI15C0607).

\section{Competing Interests}

The authors have declared that no competing interest exists. 


\section{References}

1. Marupanthorn K, Tantrawatpan C, Kheolamai P, Tantikanlayaporn D, Manochantr S. Bone morphogenetic protein-2 enhances the osteogenic differentiation capacity of mesenchymal stromal cells derived from human bone marrow and umbilical cord. Int J Mol Med. 2017;39(3):654-662.

2. Wang $Y$, Wu MH, Cheung MPL, Sham MH, Akiyama H, Chan D, Cheah KSE, Cheung M. Reprogramming of Dermal Fibroblasts into Osteo-Chondrogenic Cells with Elevated Osteogenic Potency by Defined Transcription Factors. Stem Cell Reports. 2017;8(6):1587-1599.

3. Hu LW, Wang X, Jiang XQ, Xu LQ, Pan HY. In vivo and in vitro study of osteogenic potency of endothelin-1 on bone marrow-derived mesenchymal stem cells. Exp Cell Res. 2017;357(1):25-32.

4. Ottewell PD. The role of osteoblasts in bone metastasis. J Bone Oncol. 2016;5(3):124-127.

5. Kang JH, Ko HM, Moon JS, Yoo HI, Jung JY, Kim MS, Koh JT, Kim WJ, Kim $\mathrm{SH}$. Osteoprotegerin expressed by osteoclasts: an autoregulator of osteoclastogenesis. J Dent Res. 2014;93(11):1116-1123.

6. Ren H, Ren H, Li X, Yu D, Mu S, Chen Z, Fu Q. Effects of intermedin on proliferation, apoptosis and the expression of OPG/RANKL/M-CSF in the MC3T3-E1 osteoblast cell line. Mol Med Rep. 2015;12(5):6711-6717.

7. Cochran DL. Inflammation and bone loss in periodontal disease. J Periodontol. 2008;79(8 Suppl):1569-1576.

8. Bar-Shavit Z. The osteoclast: a multinucleated, hematopoietic-origin, bone-resorbing osteoimmune cell. J Cell Biochem. 2007;102(5):1130-1139.

9. Wu L, Feyerabend F, Schilling AF, Willumeit-Römer R, Luthringer BJ. Effects of extracellular magnesium extract on the proliferation and differentiation of human osteoblasts and osteoclasts in coculture. Acta Biomater. 2015;27:294-304.

10. An J, Hao D, Zhang Q, Chen B, Zhang R, Wang Y, Yang H. Natural products for treatment of bone erosive diseases: The effects and mechanisms on inhibiting osteoclastogenesis and bone resorption. Int Immunopharmacol. 2016;36:118-131.

11. Park BW, Hah YS, Kim DR, Kim JR, Byun JH. Osteogenic phenotypes and mineralization of cultured human periosteal-derived cells. Arch Oral Biol. 2007;52(10):983-989.

12. Lee JH, Hah YS, Cho HY, Kim JH, Oh SH, Park BW, Kang YH, Choi MJ, Shin JK, Rho GJ, Jeon RH, Lee HC, Kim GC, Kim UK, Kim JR, Lee CI, Byun JH. Human umbilical cord blood-derived CD34-positive endothelial progenitor cells stimulate osteoblastic differentiation of cultured human periosteal-derived osteoblasts. Tissue Eng Part A. 2014;20(5-6):940-953.

13. Walsh MC, Choi Y. Biology of the RANKL-RANK-OPG System in Immunity, Bone, and Beyond. Front Immunol. 2014;5:511.

14. Kim JH, Kim K, Youn BU, Lee J, Kim I, Shin HI, Akiyama H, Choi Y, Kim N. Kruppel-like factor 4 attenuates osteoblast formation, function, and cross talk with osteoclasts. J Cell Biol. 2014;204(6):1063-1074.

15. Luo J, Yang Z, Ma Y, Yue Z, Lin $\mathrm{H}, \mathrm{Qu} G$, Huang J, Dai W, Li C, Zheng C, Xu L, Chen H, Wang J, Li D, Siwko S, Penninger JM, Ning G, Xiao J, Liu M. LGR4 is a receptor for RANKL and negatively regulates osteoclast differentiation and bone resorption. Nat Med. 2016;22(5):539-546.

16. Patil R, Kumar BM, Lee WJ, Jeon RH, Jang SJ, Lee YM, Park BW, Byun JH, Ahn CS, Kim JW, Rho GJ. Multilineage potential and proteomic profiling of human dental stem cells derived from a single donor. Exp Cell Res. 2014;320:92-107.

17. Aggarwal R, Lu J, Kanji S, Joseph M, Das M, Noble GJ, McMichael BK, Agarwal S, Hart RT, Sun Z, Lee BS, Rosol TJ, Jackson R, Mao HQ, Pompili VJ, Das H. Human umbilical cord blood-derived CD34+ cells reverse osteoporosis in NOD/SCID mice by altering osteoblastic and osteoclastic activities. PLoS One. 2012;7(6):e39365

18. Sidney LE, Branch MJ, Dunphy SE, Dua HS, Hopkinson A. Concise review: evidence for CD34 as a common marker for diverse progenitors. Stem Cells. 2014;32(6):1380-1389.

19. Mehrishi JN, Bakács T. A novel method of CD34+ cell separation from umbilical cord blood. Transfusion. 2013;53(11):2675-2680.

20. Shao $C$, Chen J, Chen P, Zhu M, Yao O Gu P, Fu Y, Fan X. Targeted transplantation of human umbilical cord blood endothelial progenitor cells with immunomagnetic nanoparticles to repair corneal endothelium defect. Stem Cells Dev. 2015;24(6):756-767.

21. Balint B, Ivanović Z, Petakov M, Taseski J, Jovcić G, Stojanović N, Milenković $P$. The cryopreservation protocol optimal for progenitor recovery is not optimal for preservation of marrow repopulating ability. Bone Marrow Transplant. 1999;23(6):613-619.

22. Shivakumar SB, Bharti D, Subbarao RB, Jang SJ, Park JS, Ullah I, Park JK, Byun JH, Park BW, Rho GJ. DMSO- and Serum-Free Cryopreservation of Wharton's Jelly Tissue Isolated From Human Umbilical Cord. J Cell Biochem. 2016;117(10):2397-2412

23. Marolt D, Rode M, Kregar-Velikonja N, Jeras M, Knezevic M. Primary human alveolar bone cells isolated from tissue samples acquired at periodontal surgeries exhibit sustained proliferation and retain osteogenic phenotype during in vitro expansion. PLoS One. 2014;9(3):e92969.

24. Flynn JM, Spusta SC, Rosen CJ, Melov S. Single cell gene expression profiling of cortical osteoblast lineage cells. Bone. 2013;53(1):174-181.

25. Montano Almendras CP, Thudium CS, Löfvall H, Moscatelli I, Schambach A, Henriksen K, Richter J. Forced expression of human macrophage colony-stimulating factor in CD34+ cells promotes monocyte differentiation in vitro and in vivo but blunts osteoclastogenesis in vitro. Eur J Haematol. 2017;98(5):517-526

26. Marino S, Logan JG, Mellis D, Capulli M. Generation and culture of osteoclasts. Bonekey Rep. 2014;3:570.

27. Atkins GJ, Kostakis P, Welldon KJ, Vincent C, Findlay DM, Zannettino AC. Human trabecular bone-derived osteoblasts support human osteoclast formation in vitro in a defined, serum-free medium. J Cell Physiol. 2005;203(3):573-582.

28. Maitra R, Follenzi A, Yaghoobian A, Montagna C, Merlin S, Cannizzo ES, Hardin JA, Cobelli N, Stanley ER, Santambrogio L. Dendritic cell-mediated in vivo bone resorption. J Immunol. 2010;185(3):1485-1491.

29. Franceschetti T, Kessler CB, Lee SK, Delany AM. miR-29 promotes murine osteoclastogenesis by regulating osteoclast commitment and migration. J Biol Chem. 2013:288(46):33347-33360.

30. Kim HY, Lee JH, Yun JW, Park JH, Park BW, Rho GJ, Jang SJ, Park JS, Lee HC, Yoon YM, Hwang TS, Lee DH, Byun JH, Oh SH. Development of Porous Beads to Provide Regulated BMP-2 Stimulation for Varying Durations: In Vitro and In Vivo Studies for Bone Regeneration. Biomacromolecules. 2016;17(5):1633-1642

31. Balsa JA, Lafuente C, Gómez-Martín JM, Galindo J, Peromingo R, García-Moreno F, Rodriguez-Velasco G, Martínez-Botas J, Gómez-Coronado D, Escobar-Morreale HF, Botella-Carretero JI. The role of serum osteoprotegerin and receptor-activator of nuclear factor-kB ligand in metabolic bone disease of women after obesity surgery. J Bone Miner Metab. 2016;34(6):655-661.

32. Hofbauer LC, Heufelder AE. The role of receptor activator of nuclear factor-kappaB ligand and osteoprotegerin in the pathogenesis and treatment of metabolic bone diseases. J Clin Endocrinol Metab. 2000;85(7):2355-2363.

33. Ueda T, Yoshida M, Yoshino H, Kobayashi K, Kawahata M, Ebihara Y, Ito M, Asano S, Nakahata T, Tsuji K. Hematopoietic capability of CD34+ cord blood cells: a comparison with CD34+ adult bone marrow cells. Int J Hematol. 2001;73(4):457-462

34. Murohara T, Ikeda H, Duan J, Shintani S, Sasaki Ki, Eguchi H, Onitsuka I, Matsui K, Imaizumi T. Transplanted cord blood-derived endothelial precursor cells augment postnatal neovascularization. J Clin Invest. 2000;105(11):1527-1536

35. Perucca S, Di Palma A, Piccaluga PP, Gemelli C, Zoratti E, Bassi G, Giacopuzzi E, Lojacono A, Borsani G, Tagliafico E, Scupoli MT, Bernardi S, Zanaglio C, Cattina F, Cancelli V, Malagola M, Krampera M, Marini M, Almici C, Ferrari S, Russo D. Mesenchymal stromal cells (MSCs) induce ex vivo proliferation and erythroid commitment of cord blood haematopoietic stem cells (CB-CD34+ cells). PLoS One. 2017;12(2):e0172430. 